Article

\title{
Post-Monolingual Research Methodology: Multilingual Researchers Democratizing Theorizing and Doctoral Education
}

\author{
Michael Singh \\ School of Education, Western Sydney University, Penrith, NSW 2751, Australia; \\ m.j.singh@westernsydney.edu.au \\ Academic Editor: James Albright \\ Received: 29 September 2016; Accepted: 25 January 2017; Published: 20 February 2017
}

\begin{abstract}
This paper reports on the ground-breaking research in the study of languages in doctoral education. It argues for democratizing the production and dissemination of original contributions to knowledge through activating and mobilizing multilingual Higher Degree Researchers' (HDRs) capabilities for theorizing through them using their full linguistic repertoire. This paper contributes to this study's development of post-monolingual research methodology which provides a theoretic-pedagogical framework for multilingual HDRs (a) to use their full linguistic repertoire in their research; (b) to develop their capabilities for theorizing and (c) to construct potentially valuable theoretical tools using metaphors, images, concepts and modes of critique. This paper is based on a longitudinal program of collaborative research whereby monolingual Anglophone and multilingual HDRs jointly developed their capabilities for theorizing through producing Anglo-Chinese analytical tools, and the associated pedagogies for using their languages in doctoral research. This longitudinal research program has been undertaken in the field of doctoral education to further a defining feature of democracy, namely linguistic diversity. This research has been conducted with the aims of promoting the multilingualism of Australian universities and activating linguistic communities of scholars to use their full linguistic repertoire in their research. The main finding arising from this program of research has been the development of post-monolingual research methodology which (a) uses the divergences within and between languages to undertake theorizing and $(b)$ in co-existence with the tensions posed by monolingualism, especially the insistence on using extant theories available in only one language. Doctoral pedagogies of intellectual/racial equality provide multilingual HDRs with insights into the debates about the geopolitics governing the use of languages in the production and dissemination of theoretical knowledge and the capabilities for theorizing. Often, from an English-only monolingual mindset, difference and divergence are seen as a recipe for deficits and dissonance. However, this paper challenges such mistaken beliefs by showing that multilingual HDRs can deepen and extend their capabilities for theorizing by using their own linguistic repertoires. Post-monolingual research methodology is to be of enormous benefit to multilingual researchers and scholars engaged in intellectual labor in predominantly English-only monolingual universities.
\end{abstract}

Keywords: capabilities for theorizing; collaborative monolingual/multilingual research; English-only monolingualism; intellectual equality; linguistic repertoire; multilingual Higher Degree Researchers; multilingual researchers; pedagogies of intellectual/racial equality; post-monolingual research methodology; racial equality 


\section{Introduction}

This paper introduces post-monolingual research methodology, a ground-breaking theoretic-pedagogical framework for doctoral education whereby Multilingual Higher Degrees Researchers (MHDRs) can:

1. make original contributions to theoretical knowledge by using concepts, metaphors, images and modes of critical thinking from their full linguistic repertoire, and

2. deal with the tensions created by English-only monolingual theory, research and education, including rigidities associated with just using English and theories available in English.

This paper explores how doctoral education might develop Multilingual Higher Degree Researchers' capabilities for theorizing by using their full linguistic repertoire for producing and disseminating original contributions to research-driven knowledge [1]. 'Repertoires of linguistic resources' refers to the total array of intellectual resources that multilingual HDRs have accumulated or can access, and employ in theorizing. Here, multilingualism designates two interrelated dimensions. First, multilingualism refers to the many variations in HDRs' linguistic repertoires; the knowledge they have or can access through those repertoires, and capabilities they have for using those repertoires for theorizing. Second, multilingualism also designates particular social contexts in which multilingual HDRs' practices of languages are enacted, constrained or erased, and in doing so gives rise to a diversity of 'multilingualisms' within and across universities. For instance, in the Australian Council of Learned Academies which privileges English-only monolingualism, multilingual HDRs are designated by the term "non-English speaking backgrounds" [2]. This deliberate use of the label 'non-English speaking background HDRs refused to explicitly acknowledge their full linguistic repertoire. This questionable label signifies parallel or serial 'monolingualisms', whereby English is to be used at university, and others are designated 'home languages' and restricted to domestic rather than scholarly use. This is despite the multilingual shadow work [3] undertaken in other languages to conduct their doctoral research. Multilingual shadow work refers to the unrecognized and acknowledged uses that multilingual HDRs make of their full linguistic repertoire to support their original contributions to knowledge. However, in multilingual nations such as Australia, the UK and the USA management of research training systems reduces "language" and "academic literacy" in "English".

The purpose of this paper is to verify the capabilities of multilingual HDRs who speak English and Zhongwen (Mandarin) (among other languages or dialects) for using their knowledge of concepts, metaphors, images and modes of critical thinking in Zhongwen to develop their capabilities for theorizing through an Anglo-Zhongwen matrix. In doing so, this paper builds on related research which explores the reasons for, and ways in which multilingual HDRs might use their full linguistic repertoire (a) to engage in developing their capabilities theorizing and (b) to make original contributions to knowledge as a consequence [4]. It seems reasonable to presuppose that multilingual HDRs can draw upon intellectual resources from their full linguistic repertoire to develop their theorizing, and perhaps to assess the adequacy of existing theoretical explanations. But is this really possible, given that theorizing in English is a major challenge [5]? Crossing the boundaries among divergent languages, intellectual cultures, disciplinary domains and research practices presents many struggles; not all of which can be addressed in this paper.

\subsection{Current Research Informing Post-Monolingual Research Methodology}

The vast majority of languages used by domestic students 'at home' are not being used in/for their education in Australian universities. Few MHDRs are using their language to produce knowledge as part of their doctoral education (for exceptions see papers in this special edition of Education Sciences). Appendix A provides a list of languages $(n=152)$ used by Australian domestic university students; they are not international students, whose languages would add to this number [6] (Table 9.2, 2015). From a monolingual perspective, they are attending Australian universities, where English is the medium of instruction, and they must only use English to further their education. But, then again, 
these multilingual students are Australian citizens who might reasonably expect that their university education would activate their prior knowledge of languages through appropriate learning experiences to extend and deepen their knowledge, including the knowledge they have of these languages [7]. Given that blended learning is well-entrenched in these universities, it is also useful to note that Wikipedia entries are available in 295 languages, approximately $5 \%$ of all the languages of the people of the world. Likewise, YouTube can be navigated in 76 languages, with caption support for 165 languages. However, university research is conducted by only a small number of people in just a few languages, meaning that academic knowledge of/for/about the people of the world is skewed towards what is known in English [8]. Not surprisingly, for reasons of status among others, multilingual HDRs themselves can easily, but mistakenly who equate knowledge in English with 'the language' of knowledge production and theorizing.

The increasing numbers of multilingual HDRs now provides English-only, monolingual universities educational contexts for their internationalization through making rich theoretic-linguistic connections [9]. The internationalization of education has stimulated scholarly debates over language norms and theoretical priorities. Demographic changes brought by such internationalization of education are bringing to the fore questions about who does theorizing and in what languages. The commoditization of education for the local/global knowledge economy has changed the character and functions of these universities. Multilingualism is increasingly seen as having a role in research in these universities, especially in the education of Higher Degree Researchers [10]. Multilingual HDRs are affecting the local/global dynamics of language use and the production of theoretical knowledge.

Despite claims that English-only, monolingual universities have become internationalized, multilingual HDRs report difficulties, uncertainties and dissatisfaction with constraints imposed by the prevailing worldview of these institutions [11]. This agenda has been in play for decades. For instance, for much of Edward Said's [12] schooling in Egypt, Arabic was forbidden, being effectively wrung out of him. The internationalization of education is a key mechanism for affecting linguistic standardization, with the scholarly landscape now being statured with English medium instruction and research [13]. The demand for linguistic uniformity is passed off as legitimate, right and necessary, especially for the convenience of marketing products such as English and theories in English. The negativity towards multilingualism within these universities reflects resentment to forms of knowledge that they do not or cannot control [14]. Together, these actions fix theorizing in English and arrest possibilities for theorizing in other languages.

The marginalization of non-Western theoretic-linguistic resources in research undertaken in English-only, monolingual universities constrains local/global flows in innovative knowledge production [15]. The claims that English is the language for the production of theoretical knowledge and a necessary vehicle for connecting local/global intellectual currents are being questioned [16]. There are efforts to recognize multilingual HDRs as epistemic agents who can contribute new analytical tools for theorizing a range of phenomenon in the Humanities, Arts and Social Sciences (HASS) [17]. However, to substantially redress this marginalization of the theorizing possible in the languages othered by English-only, monolingual universities requires pedagogies of intellectual/racial equality to verify the presupposition that multilingual HDRs have these capabilities [18].

Post-monolingual research methodology is directed at deepening multilingual HDRs' capabilities for theorizing, as a supplement to them using existing theories which are mostly produced and/or available in English [19]. 'Theory' and 'theorizing' are multivalent if not troublesome concepts [20]. Increasingly, educational researchers are expected to develop the capabilities required for theorizing. Meta-theoretical questions concerning how to theorize are increasingly being explicitly addressed and debated within the international academic community. Researchers are discussing the place of theorizing in research methods and ways for researchers to develop their capabilities for theorizing [21]. The meaning of theory and theorizing are contested across HASS disciplines and among researchers, with rational disagreements about what theory and theorizing are supposed to be or ought to be [22]. For instance, a theory might be seen as a critical, plausible and coherent account of social phenomenon 
that provides a persuasive explanation of how arose and why it might be dealt with in specified ways [23]. Theory can involve the elaboration of the classical scholarship, observations, formulae and speculations through concepts, conceptual frameworks, principles and models that are constituents of theory, as is disciplined imagination [24]. Theory is also thought of as a lens through which researchers study a phenomenon to produce significant, unexpected or surprising advances in knowledge, rather than confirming what is taken for granted [25]. Such theory offers understandings that make sense of the world, providing systematic reasons for a particular phenomenon and help guide future actions.

However, there is a problem here. The long-established problem is that "reading major theorists and writing literature review papers is often passed off as training in theory building, even though such assignments really don't teach one how to craft conceptual arguments" [26] (p. 380). Existing theories (mostly those in English) are distilled, packaged and transmitted across generations of researchers through research training. This problem continues today, with HDRs being "exposed to finished theories and are not aware of the process that goes into the production and design of a theory [27]. Theory and theorizing operate along a continuum rather dichotomously. Theorizing is practiced with the guidance of existing theory, and builds on existing theory in a given field [28]. Rather than learn how theories might be developed, they only get to know theory when it has been developed and published. HDRs need to develop their capabilities for theorizing which is a nonlinear process of trial-and-error involving speculation, concepts, typologies, models and explanations. Theorizing requires "disciplined imagination" and includes the activities of "abstracting, generalizing, relating, selecting, explaining, synthesizing, and idealizing" [29] (p. 389). Theorizing is the capability to make sense of evidence using concepts and reasoning to offer credible interventions that are likely to make a desirable difference. The creative intellectual work of theorizing is useful for making an original contribution to knowledge. Thus, deepening multilingual HDRs' capabilities for theorizing is not a matter of teaching them to test existing theory in English, whether that is southern theory or Confucian theory [30].

There is yet another problem to consider here. HDRs learn that theory is the language that allows them to move through their evidence to make sense of it [31]. However, seldom do the discussions about theorizing deal with the languages which might be brought to bear to develop multilingual HDRs' capabilities for theorizing. Even less consideration is given to what benefits might arise from multilingual HDRs using their full linguistic repertoire for theorizing. Moreover, little attention is given to understanding the historical role of languages and their translation to theory and theorizing [32]. In Britain, there are concerns about the threat to research productivity due to the decline in language learning and the demands on the limited number of multilingual researchers [33]. There are arguments for the international standing of scholarly journals to be defined by evidence of them publishing research in multiple languages, thereby giving recognition to the world's multilingual researchers' contributions to knowledge [34].

There is, however, another problem here. This paper invites a serious-minded, scholarly consideration of the possibilities for, and the potential benefits of extending multilingual HDRs' capabilities for theorizing through them using their full linguistic repertoire. Thus, post-monolingual research methodology should not be reduced to an exercise in bringing these HDRs' "voices" into research-driven knowledge production and dissemination. Often, in English-only monolingual practices, international students, Asian immigrants, African refugees and Indigenous people's 'voices' are used as data sources to test existing Anglo-American theories [35]. In other words, what counts as theoretical knowledge is determined by the power of Anglo-American intellectual interests theorizing 'other' voices while marginalizing others' theorizing [36]. Thus, the research reported here is not an exercise in mainstreaming of multilingual HDRs" "voices". Theorizing requires high-level reasoning, and for multilingual researchers, who elect to use their full linguistic repertoire, to use their imaginations.

Integral to the tensions constitutive of post-monolingual research methodology is yet another problem. International education sees ever more ethno-linguistically diverse students from all over the world who have moved to study in Anglo-American universities. Within a monolingual 
mindset, the fluidity and heterogeneity characteristic of multilingualism is now treated as a novel discovery called 'superdiversity'. Apparently, this has supposedly created what is imagined to be the super-dimensional, super-problem of 'superdiversity' for Anglo-American universities which privileges White, Western-centric English [37]. Edwards argues that "superdiversity is an... unnecessary term coined to suggest a non-existent development" [38] (p. 34). Further, 'superdiversity' reinforces the homogenization of socio-cultural groups; uncritically embraces elite neoliberal politics, and unthinkingly clasps to questionable concepts of culture and identity [39]. Moreover, 'super-diversity' erases the history of diverse language practices among the world's minoritized populations; obliterates norms that have plagued efforts to analyze these language practices; does not account for the neoliberal merging of state, corporate and military interests that enable and limit population mobility, and privileges monolingualism of standardized nation-state languages [40]. That the notion of 'superdiversity' overlook thousands of years of scholarship on linguistic diversity is the result of an English-only monolingual theory [41]. That this Anglo-American notion originated in a country where an anti-immigration 'juggernaut' (Hindi) drove the Brexit vote(s) is ironic given the multilingual complexity and heterogeneity of the world's English language. Taking the mixing of the languages of multilingual HDRs as the norm entails 'questioning' (French) just such English-only monolingualism which, for instance, mistakenly asserts that the Sanskrit concept of 'avatar' is an English word.

In sum, languages are necessary and important for theorizing. The concept of theoretic-linguistic tools reinforces the point that both theory and theorizing are expressed in languages. Thus, multilingual HDRs use theoretic-linguistic tools for analytical purposes and to declassify the division of intellectual labor which assigns theory to English, and data to other languages [42]. Ontologically, research-driven production of knowledge is necessarily conducted in a specific language. For instance, it is often taken for granted that multilingual HDRs will use the English language as privileged by their university for studying theory. However, post-monolingual research methodology is a vehicle for extending multilingual HDRs' capabilities for theorizing through using their full linguistic repertoire in the expectation that they might make original contributions to knowledge [43]. Through post-monolingual research methodology, multilingual HDRs explore the intellectual divergences in their full linguistic repertoire to produce resources for theorizing [44]. Thus, the concept of 'Zhongwen theoretic-linguistic tools,' for example, refers to concepts, metaphors, images and modes of critical thinking in Zhongwen which can be used as analytical concepts in research written in English. The caveat here is that 'Zhongwen theoretic-linguistic tools' do not refer to a particular ethno-national essence of Chinese-ness or to any uniqueness of these tools that is peculiar to Chinese people or Zhongwen. The use of this term is similar to Jullien's notion of "Chinese thought, [which designates] the thought which has been expressed in Chinese... in the same way 'Greek thought' is that which is expressed in Greek" [45] (p. 147). Thus, the notion of Zhongwen theoretic-linguistic tools means bringing into play the intellectual divergences within Zhongwen, and between concepts expressed in Zhongwen and English for the purpose of theorizing.

\subsection{Aim and Main Conclusions}

The aim of the research reported here is to verify that multilingual HDRs can develop their capabilities for theorizing through using concepts, metaphors, images and modes of critical thinking in Zhongwen. In other words, the aim was to enhance multilingual HDRs' capabilities for establishing a scholarly relationship between theoretical tools from the knowledge they know or can access in one language, and new knowledge of theory that they are learning to use in another language. Through introducing these theoretical tools into their English language theses, they produce an Anglo-Zhongwen matrix as an original contribution to knowledge.

The main conclusions from the longitudinal program of research to which this paper contributes, is that the presupposition that at least some multilingual HDRs have the capabilities for theorizing using their full linguistic repertoire, and that in doing so they must engage with tensions posed by 
English-only monolingualism and the privileging of Anglo-American knowledge. In other words, post-monolingual research methodology refers to situations where (a) the divergences with and between two or more languages are used to undertake theorizing, albeit (b) in co-existence with the strains posed by the taken-for-granted insistence on using extant theories available in English. Multilingual HDRs who employ post-monolingual research methodologies have had to deal with the pressures posed by monolingual English-speaking reviewers of theses, publications and grant applications. They have had to strengthen their arguments and reasoning when some reviewers found the use of metaphors, images, concepts and modes of critical thinking from other languages for theorizing disconcerting, obscure or even pointless. In effect, post-monolingual research methodology names the tensions posed by the established orthodoxy of English-only monolingualism, which is sanctified variously by legislation and educational practices as much as it appeals to selected traditions and homogenizing standards.

\section{A Longitudinal Multi-Cohort Study: Collaborative Monolingual/Multilingual Research Methods}

A longitudinal, multi-cohort study, using collaborative monolingual/multilingual research methods was designed to generate evidence which could verify or refute the presupposition that multilingual HDRs can develop their theorizing capabilities using their full linguistic repertoire. This research design was used to identify:

1. The potential of post-monolingual research methodology across this time with changing cohorts of multilingual HDRs;

2. The changes that the post-monolingual research methodology produced in the multilingual HDRs' capabilities and willingness to use their complete linguistic repertoire to theorize, and

3. The changes warranted in this post-monolingual research methodology itself as a result of multilingual HDRs' demonstrated capabilities for theorizing.

In terms of scope, this longitudinal multi-cohort study involved repeated interventions with 79 multilingual HDRs beginning in 2008. A pilot study was undertaken prior to this [46]. In addition to speaking English, these multilingual HDRs also spoke various languages. To date, most of the multilingual HDRs who participated in this research have been proficient in English and Zhongwen; others have spoken English and either Tamil, Hindi or Vietnamese. This paper focuses on HDRs who speak Zhongwen, who account for $6.8 \%$ of the languages most commonly spoken by domestic Australian students [47].

This longitudinal, multi-cohort study consisted of three interrelated strands. First, all these multilingual HDRs were presented with educational experience, including seminars and workshops devoted to exploring the project's developing knowledge of post-monolingual research methodology as part of their multi-stranded research education. However, some experienced tensions with regard to using Zhongwen in their research [48]. A few doubted the value that they themselves and others might place on the use of Zhongwen theoretic-linguistic resources in their research. Others were concerned about the merits of shaping their professional trajectory through practices involving the use of the full linguistic repertoire. Some were reluctant to use their full linguistic repertoire because they took a monolingual approach to further developing their proficiency in English. Others were reticent because of concerns about resistance to expressions of multilingualism in universities which privilege English-only monolingualism. Others preferred to use existing theories available in English; something which all HDRs need to do. Having read the work of leading theorists published in English, some were anxious about theorizing, not seeing themselves as having the intellectual authority for such an undertaking. Some found that the limited time they had for their doctoral research, along with financial and university management pressures drove them to avoid the risk of making such an original contribution to knowledge.

A second strand of this research involved those multilingual HDRs who elected to use Zhongwen and English to talk about, read for, and to write aspects of their research. In accordance with ethical 
requirements governing voluntary participation in this research project, this self-selected sample of multilingual HDRs were willingly engaged in this project. The defining characteristics that these 10 volunteers shared included being multilingual HDRs; having a shared educational experience in studying post-monolingual research methodology in-depth; a willingness to develop their theorizing capabilities through using their full linguistic repertoire in their doctoral research, and a commitment to producing jointly-authored publications to develop their capabilities for disseminating this knowledge. These particular multilingual HDRs elected to venture into an intellectual world beyond monolingualism and existing theories in English. Like other international students educated outside of North America [49], they were excited by the challenge of developing their theorizing capabilities, recognizing the large stock of metaphors, images, concepts and modes of critique that they could access in both English and Zhongwen. They were quite open minded, and were not locked into fetishizing existing theories in English. Some saw the use of their full linguistic repertoire as enabling them to produce interesting theoretical work at the intersection of different languages and disciplines, and possibly expanding the fields of knowledge within which their theorizing was undertaken. As travelers who journeyed to different places where academics spoke different languages, these multilingual HDRs worked to introduce new ideas from their languages as part of their mission [50].

These 10 multilingual HDRs employed post-monolingual research methodologies in their higher degree theses which addressed a range of topics. Some HDRs directly investigated the uses of multilingual students' full linguistic capabilities in their university education. Others incorporated post-monolingual research methodologies into their studies of service learning in higher education:

1. using HDRs' multilingual capabilities to make original contributions to knowledge;

2. using funds of theoretical knowledge in Zhongwen for research;

3. multilingual HDRs' intellectual agency in Anglophone teacher education;

4. pedagogies for the transnational, reciprocal exchange of higher order knowledge;

5. using teachers' technological, pedagogical and content knowledge for cross-sociolinguistic language education, and

6. sociocultural literacy learning for young children.

The four cases below have been selected from these theses, all of which are publically available on the University's website:

1. democratizing research education conducted in the English language;

2. embodying the teaching/learning of Zhongwen;

3. an Australian/Chilean professional development program for early childhood educators, and

4. modes of critical thinking in Zhongwen.

A third strand of this study involved the collaborative monolingual/multilingual research methods used in this program of research involving the co-construction of theoretical tools and reciprocal learning. In effect, this method brings to the fore the place of racial/intellectual equality in theorizing and knowledge production [51]. This necessarily brings into question the existing, stratified theoretic-linguistic order, its systems of inequality, and the norms used to justify such inequality [52]. The focus of this method on intellectual/racial equality means verifying the presupposition that multilingual HDRs speak languages in which they can theorize, and do not just emit noises. This focus on intellectual/racial equality is preferable to dividing researchers into categories of intelligent and capable English-speakers, as opposed to incapable and stupid non-English speakers [53]. Claims for racial/intellectual equality are grounded in democracy and the democratization of production of intellectual goods, such as theories. Democracy is defined as a shared entitlement to participate in intellectual activities which advance the egalitarian view that anyone can theorize if they have the will and the conditions to invest in the work required [54]. Moreover, their theorizing can be informed by an impulse to present a well-rounded humane view of people, and is not determined 
or exclusively shaped by a pre-fixed identity or location. Such was the unreasonable yearning of the 12 multilingual HDRs to theorize that they drew their full linguistic repertoire into doing so [55]. They rejected the Anglophone convention that views multilingual HDRs from China as merely producers of data which is then analyzed using theories produced in English. Instead, by conceptualizing themselves as epistemic agents with multilingual capabilities, they could challenge the Anglophone constructions of them as empirical objects, while engaging in theorizing that might extend or even challenge English-only theories. Accordingly, pedagogies of racial/intellectual equality encourage the diversification and hybridization of HASS research through engagement with theoretical tools from the world's multilingual knowledge producers. Contrary to English-only monolingualism, such pedagogies are directed at activating, mobilizing and deploying the resources of all human intelligence [56]. The rationale for using pedagogies of racial/intellectual equality to explore new possibilities for theorizing and new ways of making original contributions to knowledge is grounded in studies of education [57].

The next section presents evidence of four multilingual HDRs' efforts to develop their theorizing capabilities by introducing theoretical tools from Zhongwen into theses principally written in English. It should be noted that this evidence is part of a systematic, longitudinal research project that has sought to produce trustworthy and credible knowledge about the complexities of multilingual HDRs using their full linguistic repertoire for research in English-only, monolingual universities [58].

\section{Results: Multilingual HDRs Developing Their Capabilities for Theorizing}

The analytical focus here is on verifying the capabilities of multilingual HDRs using metaphors, images, concepts and modes of critical thinking in Zhongwen to construct theoretic-linguistic tools and develop their capabilities for theorizing. Initially, these HDRs had thought of English as the font of theory. Three dimensions of theorizing have been important to the studies summarized below, namely:

1. situating the use of metaphors, images, concepts and critical thinking as theoretical tools in reference to relevant literature;

2. bringing forward, defining and constituting metaphors, images, concepts and modes of critique from Zhongwen as theoretic-linguistic tools, and

3. using these theoretic-linguistic tools in a non-linear, iterative way to make meaningful analyses or interpretations of empirical observations or research processes.

\subsection{Metaphors}

Metaphors are used extensively in scientific research to make meaning, reason and develop understanding [59]. In other words, metaphors are not merely decorative literary devices, but part of the analytical tools that researchers used to inform their theorizing. Metaphors are analytical tools for conceptualizing and understanding one thing in terms of something else [60]. Metaphors can be a part of a well-crafted approach to theorizing, serving as a bridge to develop a logical argument by being explicitly used to provide an analysis of data. Chéngyǔ are among the seminal metaphors used in scholarly arguments in Zhongwen to either critique various socially acclaimed values and habits, or to invite readers to project critical interpretations into what remains unsaid (see Table 1). As can be seen below, they are usually made up of four hàn zì (characters). Meng [61] investigated the use of chéngyǔ to explore the potential contributions that metaphors might make to generating theoretic-linguistic tools for analyzing education. Of course, in doing so, Meng (re)interpreted, applied and tested concepts from existing theory as developed by major scholarly figures [62].

The use of chéngyǔ in educational research in English illustrates the possibilities that multilingual HDRs have for developing their capabilities for theorizing through exploring the divergences within and across their linguistic resources. In using chéngyǔ as theoretic-linguistic tools, HDRs who speak Zhongwen look beyond the intellectual horizon of English to analyze evidence of local/global knowledge flows and education. In doing so, these chéngyǔ point to opportunities for furthering 
the connections possible between intellectual cultures through the divergences within and between languages. In terms of post-monolingual research methodology, it is this divergence within and between languages in socially situated meaning for these metaphors that provides the intellectual resources for theorizing. While not using the concept of theorizing through divergent linguistic resources, Phadi and Owen's hint at its possibilities through a study of the meanings that South African people make of the words 'class,' including the metaphors available in Southern Sesotho and isiZulu that relate to it [63]. In academic English, the word 'middle class' refers to an economic category. Mahareng (Southern Sesotho) and phakhati (isiZulu) denote the middle of a space or a social position, thereby opening up possibilities for theorizing the phenomenon of 'class' in ways not captured or legitimized by the English language word.

Table 1. Chéngyǔ (metaphors) as possible analytical tools.

\begin{tabular}{ccc}
\hline Concept & Word for Word Translation & Meaning \\
\hline 教学做合一 & $\begin{array}{c}\text { “教” means teaching; “学” means learning; “做” means } \\
\text { doing, and “合一” means to combine, to unite. }\end{array}$ & $\begin{array}{c}\text { teaching, doing and learning is one } \\
\text { combined process and not three } \\
\text { separate processes }\end{array}$ \\
\hline 循序渐进 & $\begin{array}{c}\text { 循xún means 'in accordance', 序xù means 'order', 渐iiàn } \\
\text { means 'gradually', 进jin means 'progress or improve' }\end{array}$ & $\begin{array}{c}\text { making progress and improvements } \\
\text { in study/work at a reasonable pace }\end{array}$ \\
\hline
\end{tabular}

\subsection{Images}

In scientific research, it is common to use forms of visual representations for theorizing, i.e., to work out and present analyses. In science, visual images contain and convey meanings. For instance, Shteir and Lightman demonstrate the use of images such as charts, diagrams, calendars, networks and photographs as vehicles for theorizing science itself [64]. Swedberg argues that it is possible to theorize using visuals such as pictures, sketches, and diagrams to summarize an existing theory, to develop one's theorizing capabilities, and to generate new theoretical knowledge [65]. While undertaking her research in an English-only monolingual university, Gao (高) [66] took the risk of using a Hanzi (汉字)—character) as a visual means to theorize the cycles in her study (Figure 1). Using her imagination, Gao worked with 高 to explore and depict her understanding of xingzhi (行知 action/knowledge) research to capture features of its structure, movement, and forms. Thus, as a contribution to theorizing, Gao used Figure 1 to make explicit her understanding of the sequence of events in her research; their interrelationships and the path by which one influenced another. To understand Gao's theorizing of her research process, readers have to directly engage this Hanzi which brings to the fore humans' intellectual capabilities for theorizing in multimodal ways.

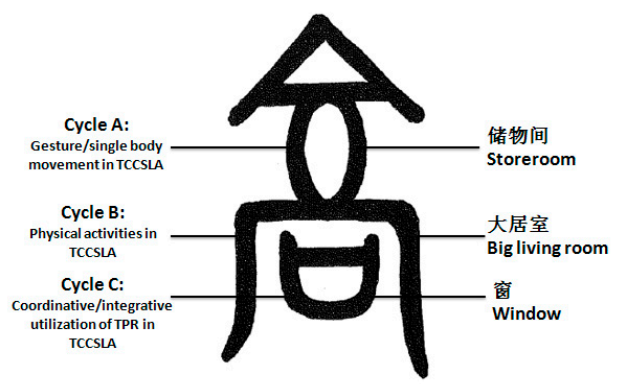

Figure 1. Using 高 (gāo) as an image to theorize xingzhi (action/knowledge) research.

Gao developed her conception of xingzhi (action/knowledge) research by making an explicit connection between what she knew about the structure of Hanzi with which she was familiar (her initial storeroom of knowledge) and the cycles of the research process through which she was engaging in professional learning, moving through the comfort of the 'big living room,' to the excitement of looking 
at new possibilities through the 'window'. She took the Hanzi that she knew intimately (高) and treated it as an image, something like a building. Gao spilt the structure of this Hanzi into the several components with which she knew (right hand side of Figure 1) and related each to the cycles employed in her research (left hand side of Figure 1). In the first cycle of her study, she drew on her existing 'storeroom' of knowledge to inform her use of single gestures or body movements in her teaching of Zhongwen. In the 'big living room', she assembled all the evidence that she collected, and then analyzed it to give her an informed direction for the second cycle of her research. The 'window' represented the third cycle of her research wherein she discovered more questions to drive future research in her field of study. Here, research is understood as an open-ended endeavor. Importantly, the 'roof' indicates that all these processes occurred within the one threptic-linguistic matrix. By treating this Hanzi as an image (i.e., 高) Gao was able to theorize the process of action/knowledge research by directly linking it to what she already knew in Zhongwen. The logic of this image provides an overall form to the xingzhi (action/knowledge) research process, with the parts positioned so that the components could relate to one another.

Post-monolingual research methodology brings into focus multilingual HDRs' full repertoire of linguistic resources, including the images which they can use to develop their capabilities for theorizing. This Hanzi (i.e., 高) is a part of Gao's everyday sociolinguistic practices. In the face of the prevailing English-only monolingual mindset in research and doctoral education, researchers are struggling to name such multilingual practices. A plethora of new terms has been developed to meet this challenge by providing more adequate explanations: codemeshing, flexible bilingualism, heteroglossia, hybrid language practices, polylanguaging, polylingual, languaging, transcultural literacy, translanguaging, transglossia and translingual practice [67]. Together, these novel concepts indicate an epistemological move away from sanctioning monolingual practices of English-only medium instruction and research, in particular the notion that languages are separate, isolated and bounded. Together, these terms open up new intellectual territory for investigation, while speaking to the tensions posed by English-only monolingual literacy norms.

\subsection{Concepts}

Concepts which are defined, explained and used as analytical tools are an important part of theorizing. Typically, the process of theorizing involves examining the definition of key concepts, some of which may be new to a given field of study. This may involve the careful redefinition of an existing concept-it may be broadened or otherwise stretched in new directions [68]. Qi [69] developed the Anglo-Zhongwen concept of "networked-hutong siwei" to explain how English-speaking monolingual educators might mobilize intellectual resources for exploring alternatives posed by the dilemmas of transnational education. Hutong is a Mongolian word which refers to narrow streets or alleys in residential communities in cities such as Beijing. Those left are now are tourist attractions. The word siwei means thinking. The notion of networked-hutong siwei names the predicament whereby transnational educators regard existing theories in English as sacred, and they are anxious about using alternative theories in Spanish. Here, hutong represents 'transnational education', a site of struggle where educators are confronted by theories in Spanish, and recognize that they too are part of the power of the world's dominating knowledge/language structures [70]. The notion of a single-hutong siwei refers to transnational educators as ensnared in an oppressive hutong, anxious for enlightened thinking to break them free. In contrast, a networked-hutong siwei refers to transnational educators thinking critically about the interconnectedness among the hutongs (and their languages and intellectual cultures), so as to open up and multiply their options for action.

Here, a novel concept, networked-hutong siwei, has been specified, clarified, and defined and used analytically. Qi's generation of this concept offers an example of a multilingual HDR exploring the possibilities for bringing forward theoretical resources from their linguistic repertoire to contribute to data analysis and informed scholarly debates. Developing a series of interrelated Anglo-Zhongwen concepts into a substantive framework is work that remains to be undertaken. 
Thus, this theorizing can be extended by tying together many concepts into a coherent framework. English-only monolingualism represents an instance of a single-hutong siwei for multilingual HDRs. By employing the concept of a networked-hutong siwei multilingualism, HDRs reach beyond theoretical concepts available in English to access the intellectual resources accessible through the world's languages [71]. A networked-hutong siwei creates possibilities for educators to make detours where they can explore the ins and outs of their full linguistic repertoire. By making their own theoretic-linguistic resources part of a collective educational research project, multilingual HDRs make a small but nonetheless significant contribution to inserting a worldly orientation in otherwise English-only monolingual education.

\subsection{Modes of Critical Thinking}

All research calls for critical thinking. Such critical thinking is important for providing a nuanced review of the literature and analyzing the evidence. Critical thinking is necessary to bring to the fore forces, imagination and connections that structure and effect perceptions, concepts and experiences. When labeled as 'Chinese' students rather than 'multilingual' students, the teaching of critical thinking to international students from China is framed in terms of teaching something alien to students who are just as alien [72]. Critical thinking is constructed as a mode of expression unique to English, supposedly alien to the intellectual norms of students in/from China.

$\mathrm{Lu}$ [73] investigated modes of critical thinking in Zhongwen on the basis of her familiarity with modes of problem posing and questioning expressed in Zhongwen. This made it necessary for her to be mindful of state censorship and the abiding sense of intellectual subjugation which impose limitations on her scholarship while studying abroad. She was also aware of the insularity of Anglo-American scholarship in critical thinking and faced pressure from university research managers to have her theses examined solely by US-centric scholars, with no regard for the sociological and epistemological issues at stake in her research [74]. Nevertheless, working with the presupposition that people in China have the capability for critical thinking [75], she set out to investigate various instances of critical thinking in the works of scholars, popular cultures and among students in China (see Table 2).

Table 2. Examples of modes of critical thinking in Zhongwen.

\begin{tabular}{|c|c|c|}
\hline Hanzi & Pinyin & English Translation \\
\hline 因材施教，因财施教 & yin cai shi jiao, yin cai shi jiao & $\begin{array}{l}\text { teaching according to aptitude (versus) } \\
\text { teaching according to money }\end{array}$ \\
\hline $\begin{array}{l}\text { 生如夏花, 却被折下 } \\
\text { 温故而知新 }\end{array}$ & $\begin{array}{l}\text { shēng rú xiahuā, què bei zhéxià } \\
\text { wēn gù er zhī xīn }\end{array}$ & $\begin{array}{l}\text { life is as summer flowers, but it is snapped off } \\
\text { Getting to the unknown through the known. }\end{array}$ \\
\hline
\end{tabular}

Critical thinking is driven by an ambition to explore the workings of power and positioning in ways that contribute to intellectual or academic freedom. For multilingual HDRs, this is important in terms of what they might see themselves saying, doing and being through using their full linguistic repertoire. Lu's study identified examples of oblique critical thinking using the profusion of homophones in Zhongwen. For instance, university students in China write “因材施教 yin cai shi jiao, meaning 'teaching according to aptitude.' They rewrite this as '因财施教 yin cai shi jiao, whereby the use of 财 instead of 材 to change the meaning to 'teaching according to money'. Similarly, the couplet 生如夏花, 却被折下 or in pinyin, shēng rú xiahuā, què bei zhéxià, means 'life is like summer flowers, but it is snapped off.' However, 生 shēng can also mean 'student.' Thus, when thought of in reference to the Chaos, this couplet may be interpreted to mean, 'The students were like summer flowers, but they suffered from the disaster of their time'.

\section{Discussion: Theorising through Intercultural Divergences within/between Language}

The theses from which the cases above have been selected, verify the capabilities that multilingual HDRs have for generating concepts, metaphors, images and modes of critical thinking within universities that privilege English and Anglo-America intellectual culture. Importantly, in each case, 
readers cannot operate in an English-only monolingual mode. The material presented in Zhongwen is elaborated in such ways that serious-minded attention has to be given to the concepts, metaphors, images and modes of critical thinking that are offered. At the very least, this makes reading such research a multilingual experience. Such multilingual theses are educationally inclusive [76] in so far as they (a) develop multilingual HDRs' capabilities for theorizing in multiple languages, and (b) introduce theoretical tools from multiple languages to the monolingual English-speaking scholarly community.

The cases above indicate ways in which multilingual HDRs may develop their theorizing capabilities using their full linguistic repertoire to construct theoretical tools for analytical uses in their research. In doing so, they are making intellectual claims that underscore their capabilities for using multiple languages; for theorizing and for having the sense and sensibilities for doing so. Typically, however, multilingual HDRs are taught to associate 'theory' with the finished products written or fashioned in English. They are trained to use existing theory to collect and analyze data. While this includes referencing works by post-colonial, Southern or Confucian theorists, this does not constitute post-monolingual research methodology. Usually, explanations and justifications about how such theory is generated are missing from publications presenting theory-as-product. Likewise, theses written by multilingual HDRs in English, with data from other languages presented only in English translation (often without the original), and citations to conceptual tools in other languages being remarkably uncommon (being marked by quotation marks or italics), offer a monolingual experience of knowledge production and theorizing. Under these circumstances, multilingual HDRs learn little about how and why major theorists actually produced their theories.

Through exploring divergences within and across languages, it becomes possible for multilingual HDRs to probe by-ways that open up theorizing beyond the singularities represented in just one language, English. The intellectual divergences within and between languages provide generative angles through which new possibilities for theorizing can be explored. In contrast, English-only, monolingualism limits multilingual HDRs' capabilities for theorizing; constrains their potential for making a contribution to original knowledge, and limits understandings of people and the world. The intellectual divergences possible through Zhongwen provide resources that serve to liberate theorizing from being the exclusive product of the English language. There are, however, some challenges involved in doing so. Theorizing involves a struggle to subtly explain why acts, events, structures and thoughts happen in the certain ways through reference to the available evidence.

There are issues to be addressed with respect to the monolingual English-speaking scholarly community in terms of introducing theoretical tools from multiple languages. Post-monolingual research methodology can help such research educators to see that the English language provides but one set of theoretical resources for making meaning of HASS phenomenon. Both multilingual HDRs and their monolingual English-speaking research educators are products of, and contributors to the many evolving, intermixing, hybrid intellectual cultures of human history [77]. Monolingual English-speaking academics benefit from such collaborative research methods by developing knowledge of the challenges of theorizing and gaining knowledge of unfamiliar theoretical tools available to those who speak other languages. Mutual learning occurs through co-constructing theoretical tools based on intellectual/racial equality.

Further, monolingual English-speaking researchers are important in catalyzing multilingual HDRs to activate, mobilize and deploy their full linguistic repertoire to develop their capabilities for theorizing. They can provide legitimacy to such moves by engaging in associated debates about the geopolitics of local/global knowledge production, research and theorizing. Moreover, monolingual English-speaking researchers can explore possibilities for the realignment of university research management which privileges English and Anglo-American theories. There are challenges here. The internationalization of Anglo-American education focuses on the transfer of higher level intellectual resources that privilege the transmission of Anglo-American theoretical knowledge by means of the English language. Not surprisingly, managers, academics and HDRs in these universities bring multiple meanings and dispositions for relating to multilingualism and English-only 
monolingualism. Technical modes of 'research training' ignore the intellectual agency of multilingual HDRs, restricting the uses that they can make of their full linguistic repertoire in their research on shadow work.

Multilingual HDRs and English-speaking monolingual research educators are part of worldly intellectual cultures. They are entangled in processes of homogenization effected through university management systems and the heterogenization borne of multilingual students, HDRs and staff. In so far as English is the only language used to bring theories into existence, this furthers intellectual homogenization and conformity. Today, such standardization is in danger of drowning theoretic-linguistic divergences throughout the whole world. However, as the process for uniformity and conformity meets resistance, the drive for original contributions to knowledge through using multilingual HDRs' linguistic repertoire increases [78]. Post-monolingual research methodology licenses the heterogeneity and divergences required for innovative knowledge production and dissemination in Mathematics, Engineering, Technology, Art and Languages (METALS). Multilingual HDRs can add value to HASS research by countering the press for standardization or Macdonaldisation in higher education [79], and by extending the intellectual resources used for theorizing through bringing forward ideas from the world's languages.

\section{Conclusions}

This paper along with the others in this special edition of Educational Sciences present evidence of post-monolingual research methodology as a useful approach which could be adopted by multilingual researchers using any number of languages. Since 2008, the research reported here has worked to verify the presupposition that multilingual HDRs can develop their capabilities for theorizing by using the intellectual divergences within/among the languages they know. These divergences provide an important angle for investigation, offering new paths to explore ways of making an original contribution to knowledge. They turn loanwords from their linguistic repertoire into theoretic-linguistic words for research reported in English. While this is a marked departure from merely celebrating cultural differences or focusing on English language deficits, post-monolingual research methodology is framed to address these recurring tensions. In doing so, this program of longitudinal research has brought to the fore:

1. intellectual merit of multilingual HDRs who understand more about theory and theorizing, and the contribution that their languages and intellectual cultures can make in this regard;

2. the importance for universities of adding value to multilingual HDRs' languages, for instance through them generating theoretic-linguistic resources;

3. significance of constructing theoretic-linguistic dialogues among intellectual cultures to advance innovations in knowledge production;

4. the importance of countering the press for standardization through English-only monolingualism and uniformity through privileging Anglo-American theoretical knowledge.

In sum, a primary concern of post-monolingual research methodology is extending multilingual HDRs' capabilities of theorizing using intellectual resources from any of their languages. Post-monolingual research methodology is framed by two interrelated but contradictory considerations. On the one hand, in order to contribute to the global stock of knowledge, it is desirable that multilingual HDRs use their full linguistic repertoire to bring forward innovative theoretic-linguistic resources. On the other hand, multilingual HDRs must deal with a situation where such capacity building and innovative contributions to knowledge is done within universities which have invested heavily in Anglo-American theoretical knowledge and privilege English-only monolingualism.

Post-monolingual research methodology sees multilingual HDRs activate, mobilize and deploy metaphors, images, concepts and modes of critique from their full linguistic repertoire in their theses (illustrated in the papers in this special edition of Education Sciences). In doing so, they engage in the risky and messy craft of theorizing using their full linguistic repertoire which includes extant 
theories in English. They have demonstrated their growing capability for generating rudimentary theoretic-linguistic tools. In doing so, they are making small but nonetheless significant contributions to pushing the epistemic boundaries of English-only, monolingual universities in a more worldly direction to recognize their HDRs' multilingual capabilities and to recognize multilingualism as the norm for knowledge production and dissemination. This approach to the 'internationalization' of education is likely to become more interesting and valuable as multilingual HDRs develop the sense and sensibilities for using their full linguistic repertoire for theorizing. By taking a position as 'multilingual HDRs', rather than deficient uses of English and Anglo-American theories, they can verify their multilingual capabilities and make known their capabilities for using their full linguistic repertoire to theorize. Some might gain recognition as post-monolingual theorists.

There is, however, no single so-called 'world's best' research methodology for realizing a worldly orientation to 'internationalizing' doctoral education. In part, this is because research directed at such ends co-exists within a tense and complex range of university political-bureaucratic and educational-linguistic-and-knowledge practices. These problems are inherent in the organizational struggles associated with securing learning transformations for intellectual/racial equality. Thus, the propositions developed in this paper invite further modification, revision, and refinement, especially by those multilingual HDRs interested in mitigating the decline in linguistic diversity and the homogenizing process for theoretic-linguistic enclosure. In particular, further research is required to investigate how interested monolingual English-speaking researchers learn to work with their multilingual counterparts to use post-monolingual research methodology. Likewise, more research is required to demonstrate how ever-more languages can be mobilized to generate theoretic-linguistic tools that can make sense of this phenomenon. Then, there is the challenging question of whether multilingual HDRs can generate concepts, metaphors, images and modes of critical thinking from outside English and Anglo-America intellectual cultures that provide HASS with innovative theoretic-linguistics tools. The multilingual HDRs in this study have been very cautious about generating theoretic-linguistic tools, being fully aware that they are not always as helpful or innovative as might be supposed. Nevertheless, the ground-breaking research reported in this paper may provoke or invite more serious consideration of the benefits of pluralizing the ways in which multilingual HDRs theorize by bringing their full linguistic repertoire to the production and dissemination of original knowledge.

Conflicts of Interest: The author declares no conflict of interest.

\section{Appendix}

Table A1. Languages Spoken at Home by Australia's Domestic University Students, Full Year 2015.

\begin{tabular}{ll}
\hline & English \\
\hline Northern European Languages & \\
\hline & Afrikaans \\
Celtic \\
Danish \\
Dutch \\
Dutch and Related Languages \\
Estonian \\
Finnish \\
German \\
German and Related Languages \\
Northern European \\
Norwegian \\
Swedish \\
languages with fewer than 20 students \\
\hline
\end{tabular}


Table A1. Cont.

\begin{tabular}{|c|c|}
\hline \multicolumn{2}{|c|}{ English } \\
\hline \multicolumn{2}{|l|}{ Southern European Languages } \\
\hline & French \\
\hline & Greek \\
\hline & Italian \\
\hline & Maltese \\
\hline & Portuguese \\
\hline & Spanish \\
\hline & languages with fewer than 20 students \\
\hline \multicolumn{2}{|l|}{ Eastern European Languages } \\
\hline & Albanian \\
\hline & Armenian \\
\hline & Bosnian \\
\hline & Bulgarian \\
\hline & Croatian \\
\hline & Czech \\
\hline & Hungarian \\
\hline & Latvian \\
\hline & Lithuanian \\
\hline & Macedonian \\
\hline & Polish \\
\hline & Romanian \\
\hline & Russian \\
\hline & Serbian \\
\hline & Serbo-Croatian/Yugoslavian, so described \\
\hline & Slovak \\
\hline & Slovene \\
\hline & Ukrainian \\
\hline & languages with fewer than 20 students \\
\hline \multicolumn{2}{|l|}{ Southwest and Central Asian Languages } \\
\hline & Amharic \\
\hline & Arabic \\
\hline & Armenian \\
\hline & Assyrian Neo-Aramaic \\
\hline & Chaldean Neo-Aramaic \\
\hline & Dari \\
\hline & Hazaraghi \\
\hline & Hebrew \\
\hline & Iranic \\
\hline & Kurdish \\
\hline & Middle Eastern Semitic Languages \\
\hline & Pashto \\
\hline & Persian \\
\hline & Persian (excluding Dari) \\
\hline & Tigrinya \\
\hline & Turkic \\
\hline & Turkish \\
\hline & Turkmen \\
\hline & Uygur \\
\hline & languages with fewer than 20 students \\
\hline
\end{tabular}


Table A1. Cont.

\begin{tabular}{|c|c|}
\hline \multicolumn{2}{|c|}{ English } \\
\hline Southern Asian Languages & \\
\hline & $\begin{array}{l}\text { Bengali } \\
\text { Fijian Hindustani } \\
\text { Gujarati } \\
\text { Hindi } \\
\text { Indo-Aryan } \\
\text { Kannada } \\
\text { Konkani } \\
\text { Malayalam } \\
\text { Marathi } \\
\text { Nepali } \\
\text { Other Southern Asian Languages } \\
\text { Punjabi } \\
\text { Sindhi } \\
\text { Sinhalese } \\
\text { Southern Asian Languages } \\
\text { Tamil } \\
\text { Telugu } \\
\text { Urdu } \\
\text { languages with fewer than } 20 \text { students }\end{array}$ \\
\hline \multicolumn{2}{|l|}{ Southeast Asian Languages } \\
\hline & $\begin{array}{l}\text { Bisaya } \\
\text { Burmese } \\
\text { Burmese and Related Languages } \\
\text { Cebuano } \\
\text { Filipino } \\
\text { Haka } \\
\text { Hmong } \\
\text { Hmong-Mien } \\
\text { Ilonggo (Hiligaynon) } \\
\text { Indonesian } \\
\text { Karen } \\
\text { Khmer } \\
\text { Lao } \\
\text { Malay } \\
\text { Other Southeast Asian Languages } \\
\text { Tagalog } \\
\text { Tagalog (Filipino) } \\
\text { Tetum } \\
\text { Thai } \\
\text { Vietnamese } \\
\text { languages with fewer than } 20 \text { students }\end{array}$ \\
\hline \multicolumn{2}{|l|}{ Eastern Asian Languages } \\
\hline & $\begin{array}{l}\text { Cantonese } \\
\text { Chinese } \\
\text { Hakka } \\
\text { Japanese } \\
\text { Korean } \\
\text { Mandarin } \\
\text { Min Nan } \\
\text { Mongolian } \\
\text { Other Eastern Asian Languages } \\
\text { Tibetan } \\
\text { Wu } \\
\text { languages with fewer than } 20 \text { students }\end{array}$ \\
\hline
\end{tabular}


Table A1. Cont.

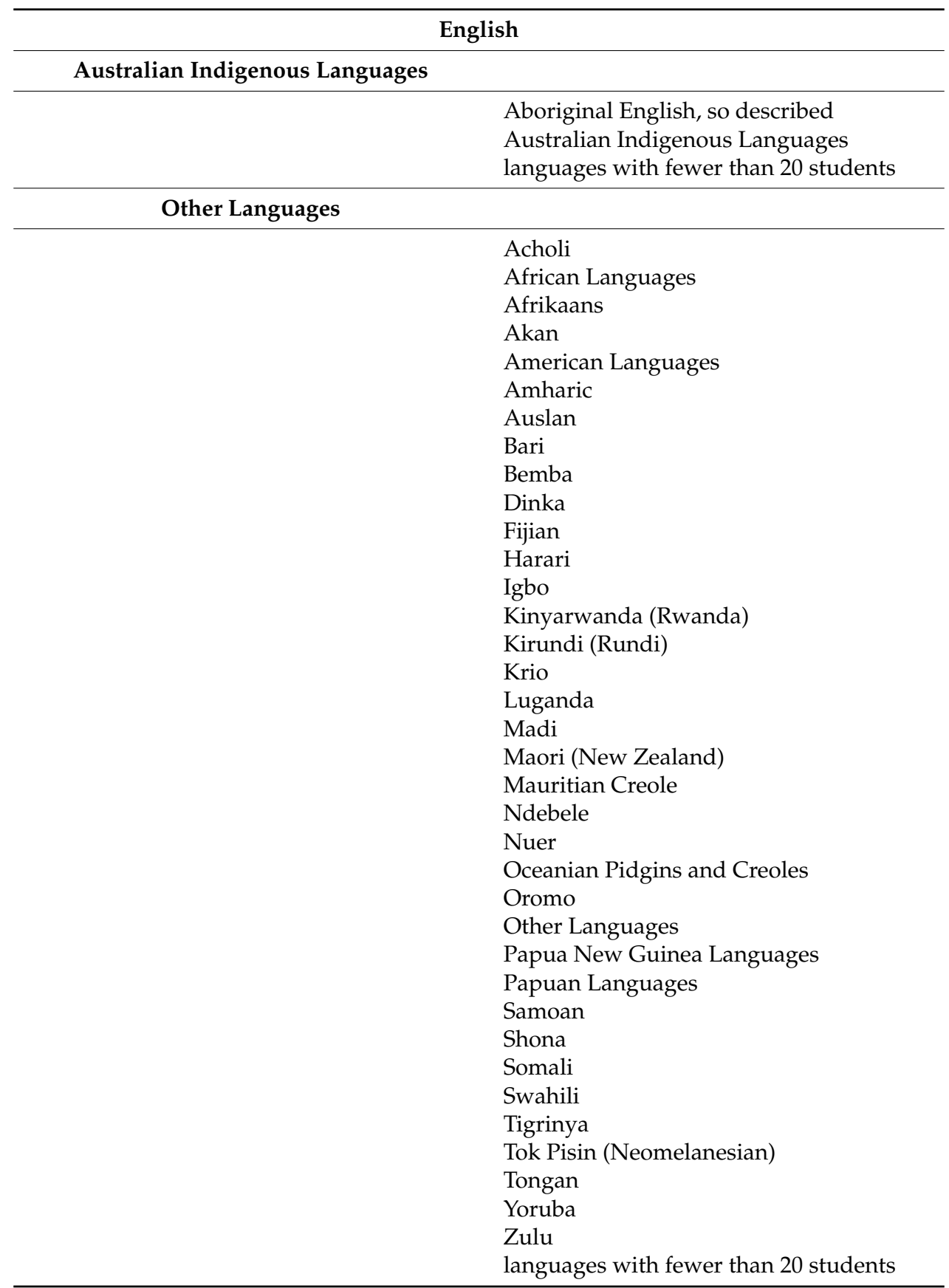

Source: Australian Government Department of Education and Training, 2015: Ethnicity related data https://docs. education.gov.au/node/41736 Table 9.2.

\section{References}

1. Singh, M. Worldly critical theorizing in Euro-American centered teacher education? In Global Teacher Education; Zhu, X., Zeichner, K., Eds.; Springer: Dordrecht, The Netherlands, 2013; pp. 141-169.

2. McGagh, J.; Marsh, H.; Western, M.; Thomas, P.; Hastings, A.; Mihailova, M.; Wenham, M. Review of Australia's Research Training System; Australian Council of Learned Academies: Melbourne, Australia, 2016.

3. Illich, I. Shadow Work; Maple-Vail: York, PA, USA, 1981.

4. Singh, M. Connecting intellectual projects in China and Australia: Bradley's international student-migrants, Bourdieu and productive ignorance. Aust. J. Educ. 2010, 54, 31-45. [CrossRef]

5. Makarychev, A.; Morozov, V. Is "non-Western theory" possible? Int. Stud. Rev. 2013, 15, 328-350. [CrossRef] 
6. Australian Government Department of Education and Training, Ethnicity Related Data. Available online: https://docs.education.gov.au/node/41736 (accessed on 15 September 2016).

7. Gurlitt, J.; Renkl, A. Are high-coherent concept maps better for prior knowledge activation? Differential effects of concept mapping tasks on high school vs. university students. J. Comput. Assist. Learn. 2008, 24, 407-419. [CrossRef]

8. House, J. English as a global lingua franca. Lang. Teach. 2014, 47, 363-376. [CrossRef]

9. Singh, M. Using Chinese knowledge in internationalising research education: Jacques Rancière, an ignorant supervisor and doctoral students from China. Glob. Soc. Educ. 2009, 7, 185-201. [CrossRef]

10. Balfour, R. University language policies, internationalism, multilingualism, and language development in South Africa and the UK. Camb. J. Educ. 2007, 37, 35-49. [CrossRef]

11. Choy, S.; Li, M.; Singh, P. The Australian doctorate curriculum. Int. J. Res. Dev. 2015, 6, 165-182.

12. Said, E. Out of Place: A Memoir; Granta Books: London, UK, 1999.

13. Gogolin, I. The 'monolingual habitus' as the common feature in teaching in the language of the majority in different countries. Per Linguam 1997, 13, 38-49. [CrossRef]

14. Doiz, A.; Lasagabaster, D.; Sierra, J. What does 'international university' mean at a European bilingual university? The role of languages and culture. Lang. Aware. 2014, 23, 172-186. [CrossRef]

15. Gordin, M. Scientific Babel; University of Chicago Press: Chicago, IL, USA, 2015.

16. Takayama, K. Deploying the post-colonial predicaments of researching on/with 'Asia' in education. Discourse 2016, 37, 70-88.

17. Ryan, J. Teaching and learning for international students. Teach. Teach. 2011, 17, 631-648. [CrossRef]

18. Singh, M. Pedagogies of intellectual equality for connecting with non-Western theories. In Precarious International Multicultural Education; Wright, H., Singh, M., Race, R., Eds.; Sense: Rotterdam, The Netherlands, 2012; pp. 237-258.

19. Singh, M.; Manathunga, C.; Bunda, T.; Qi, J. Mobilising Indigenous and non-Western theoretic-linguistic knowledge in doctoral education. Knowl. Cult. 2016, 4, 54-68.

20. Clegg, S. On the problem of theorising. High. Educ. Res. Dev. 2012, 31, 407-418. [CrossRef]

21. Marker, M. Theories and disciplines as sites of struggle. Can. J. Nativ. Educ. 2004, 28, 102-110.

22. Biesta, G.; Allan, J.; Edwards, R. The theory question in research capacity building in education. Br. J. Educ. Stud. 2011, 59, 225-239. [CrossRef]

23. Markovsky, B. Graduate training in sociological theory and theory construction. Sociol. Perspect. 2008, 51, 423-445. [CrossRef]

24. Weick, K. What theory is not, theorizing is. Adm. Sci. Q. 1995, 40, 385-390. [CrossRef]

25. Swedberg, R. On Charles' Peirce's lecture "how to theorize." Sociologica 2012, 2, 1-27.

26. Sutton, R.; Staw, B. What theory is not. Adm. Sci. Q. 1995, 40, 371-384. [CrossRef]

27. Swedberg, R. Before theory comes theorizing or how to make social science more interesting. Br. J. Sociol. 2016, 67, 5-22. [CrossRef] [PubMed]

28. Swedberg, R. Theorizing in sociology and social science. Theory Soc. 2012, 41, 1-40. [CrossRef]

29. Weick, K. Theory construction as disciplined imagination. Acad. Manag. Rev. 1989, 14, 516-531.

30. Spickard, J. Ethnocentrism, social theory and Non-Western sociologies of religion toward a Confucian alternative. Int. Sociol. 1989, 13, 173-194. [CrossRef]

31. Rudestam, K.; Newton, R. Surviving Your Dissertation: A Comprehensive Guide to Content and Process; Sage: Newbury Park, CA, USA, 1992.

32. Montgomery, S. Science in Translation; University of Chicago Press: Chicago, IL, USA, 2000.

33. Levitt, R.; Janta, B.; Shehabi, A.; Jones, D.; Valentini, E. The Supply of and Demand for UK Born and Educated Academic Researchers with Skills in Languages Other Than English; (Technical Report); RAND Corporation: London, UK, 2009.

34. Hamel, R. Engaging a plurilingual scientific community: Multiple languages for international academic publications. Anthropol. News. 2010, 51, 17. [CrossRef]

35. Moore, R.; Muller, J. The discourse of 'voice' and the problem of knowledge and identity in the sociology of education. Br. J. Sociol. Educ. 1999, 20, 189-206. [CrossRef]

36. Young, M. Education, globalisation and the 'voice of knowledge'. J. Educ. Work 2009, 22, 193-204. [CrossRef]

37. Ford, R. Acceptable and unacceptable immigrants: How opposition to immigration in Britain is affected by migrants' region of origin. J. Ethn. Migr. Stud. 2011, 37, 1017-1037. [CrossRef] 
38. Edwards, J. Multilingualism: Understanding Linguistic Diversity; Bloomsbury: London, UK, 2012.

39. Ndhlovu, F. A decolonial critique of diaspora identity theories and the notion of superdiversity. Diaspora Stud. 2016, 9, 28-40. [CrossRef]

40. Flores, N.; Lewis, M. From truncated to sociopolitical emergence: A critique of super-diversity in sociolinguistics. Int. J. Sociol. Lang. 2016, 241, 97-124. [CrossRef]

41. Piller, I. Monolingual ways of seeing multilingualism. J. Multicult. Discourses 2016, 11, 25-33. [CrossRef]

42. Singh, M. Urban education across the post-colonial, post-cold War South Pacific: Changes in the trans-national order of theorizing. In Second International Handbook of Urban Education; Pink, W., Noblit, G., Eds.; Springer: Dordrecht, The Netherlands, 2016.

43. Singh, M.; Cui, G. Internationalising Western doctoral education through bilingual research literacy. Pertan. J. Soc. Sci. Humanit. 2011, 19, 535-545.

44. Singh, M.; Qi, J. The educational travels of Tibetan knowledge. In Indigenous People; Craven, R., Bodkin-Andrews, G., Mooney, J., Eds.; Information Age Publishing: Charlotte, NC, USA, 2013; pp. 123-148.

45. Jullien, F. On the Universal, the Uninform, the Common and Dialogue between Cultures; Polity Press: Cambridge: UK, 2014.

46. Singh, M.; Fu, D. Flowery inductive rhetoric meets creative deductive arguments. Int. J. Asia Pac. Stud. 2008, 4, 121-137.

47. Parr, N. Who goes to university? The changing profile of our students. The Conversation, 25 May 2015.

48. Singh, M.; Fu, D. Are we uncritical, unfocussed, plagiarising rote learners? In Changing University Learning and Teaching; McConachie, J., Ed.; PostEd Press: Teneriffe, Autralia, 2008; pp. 261-280.

49. Schneiderhan, E. Theorizing resistance. Br. J. Sociol. 2016, 67, 43-49. [CrossRef] [PubMed]

50. Kvale, S.; Brinkman, S. Interviews; Sage: Thousand Oaks, CA, USA, 2009.

51. Tran, L.; Nguyen, N. Re-imagining teachers' identity and professionalism under the condition of international education. Teach. Teach. 2015, 21, 958-973. [CrossRef]

52. Price, D. Threatening Anthropology; Duke University Press: Durham, NC, USA, 2004.

53. Rancière, J. The Ignorant Schoolmaster; Stanford University Press: Stanford, CA, USA, 1991.

54. Hilliard, C. To Exercise Our Talents; Harvard University Press: Cambridge, MA, USA, 2006.

55. Singh, M.; Harreveld, R.; Chen, C. The presupposition of equality of theoretical assets from diverse educational cultures. In Cultural and Social Diversity and the Transition from Education to Work; Tchibozo, G., Ed.; Springer: Dordrecht, The Nethrlands, 2012; pp. 75-94.

56. Jullien, F. The Book of Beginning; Yale University Press: New Haven, CT, USA, 2015.

57. Singh, M. Translating Studies of Asia: A Curriculum Statement for Negotiation in Australian Schools; Australian Curriculum Studies Association: Canberra, Australia, 1995.

58. Singh, M.; Huang, X. Declassifying Sino-Anglo divisions over critical theorising. Compare 2013, 43, 549-566.

59. Nie, J.; Gilbertson, A.; de Roubaix, M.; Staunton, C.; van Niekerk, A.; Tucker, J.; Rennie, S. Healing without waging war: Beyond military metaphors in medicine and HIV cure research. American J. Bioeth. 2016, 16, 3-11. [CrossRef] [PubMed]

60. Lakoff, G.; Johnson, M. Metaphors We Live By; University of Chicago Press: Chicago, IL, USA, 1980.

61. Meng, H. Democratising English Language Research Education in the Face of Eurocentric Knowledge Transfer. Ph.D. Thesis, Western Sydney University, Penrith, Australia, 20 January 2012.

62. Rancière, J. Hatred of Democracy; Verso: London, UK, 2006.

63. Phadi, M.; Manda, O. The language of class: Southern Sotho and Zulu meanings of 'middle class' in Soweto. S. Afr. Rev. Sociol. 2010, 41, 81-98. [CrossRef]

64. Shteir, A.; Lightman, B. (Eds.) Figuring It Out: Science, Gender and Visual Culture; Dartmouth College: Hanover, UK, 2006.

65. Swedberg, R. Can you visualize theory? Sociol. Theory 2016, 34, 250-275. [CrossRef]

66. Gao, T. Shake Your Amazing Body. Master of Education Honours research Thesis, Western Sydney University, Penrith, Australia, 31 March 2012.

67. Kigamwa, J.; Ndemanu, M. Translingual practice among African immigrants in the US. J. Multiling. Multicult Dev. 2016, 1-12. [CrossRef]

68. Carleheden, M. What conception of the theoretical does 'theorizing' presuppose? Br. J. Sociol. 2016, 67, 36-42. [CrossRef] [PubMed] 
69. Qi, J. Multilingual Critique in Transnational Education. Ph.D. Thesis, Western Sydney University, Penrith, Australia, 30 August 2013.

70. Alatas, F. Alternative Discourses in Asian Social Science; Sage: New Delhi, India, 2006.

71. Singh, M. Learning from China to internationalise Australian research education: Pedagogies of intellectual equality and 'optimal ignorance' of ERA journal rankings. Innov. Educ. Teach. Int. 2011, 48, 395-405. [CrossRef]

72. Egege, S.; Kutieleh, S. Critical thinking: Teaching foreign notions to foreign students. Int. Educ. J. 2004, 4, $75-85$.

73. Lu, S. Chinese Modes of Critical Thinking. Ph.D. Thesis, Western Sydney University, Penrith, Australia, 30 August 2016.

74. Snowden, A. Ethics and originality in doctoral research in the UK. Nurse Res. 2014, 21, 12-15. [CrossRef] [PubMed]

75. Davies, G. Worrying about China: The Language of Chinese Critical Inquiry; Harvard University Press: New York, NY, USA, 2007.

76. Rutar, S. Multilingual learning and teaching as a principle of inclusive practice. Sodob. Pedagog. 2014, 65, $10-25$.

77. Cook, H. Matters of Exchange; Yale University Press: New Haven, CT, USA, 2007.

78. Macedo, D.; Dendrinos, B.; Gounari, P. Hegemony of English; Routledge, New York, NY, USA, 2015.

79. Hayes, D.; Wynyard, R. (Eds.) The McDonaldization of Higher Education; Information Age Publishing: Charlotte, NC, USA, 2006.

(C) 2017 by the author. Licensee MDPI, Basel, Switzerland. This article is an open access article distributed under the terms and conditions of the Creative Commons Attribution (CC BY) license (http:/ / creativecommons.org/licenses/by/4.0/). 